\title{
Intelligent Robust Feed-forward Fuzzy Feedback Linearization Estimation of PID Control with Application to Continuum Robot
}

\author{
Afsaneh Salehi \\ Research and Development Unit, SanatkadeheSabze Pasargad Company (S.S.P. Co), Shiraz, Iran \\ SSP.ROBOTIC@gmail.com \\ Farzin Piltan \\ Senior researcher at Research and Development Unit, SanatkadeheSabze Pasargad Company (S.S.P. Co), Shiraz, Iran \\ piltan_f@iranssp.com; WWW.iranssp.com \\ Mahmoud Mousavi \\ Research and Development Unit, SanatkadeheSabze Pasargad Company (S.S.P. Co), Shiraz, Iran \\ SSP.ROBOTIC@gmail.com \\ Arzhang Khajeh \\ Research and Development Unit, SanatkadeheSabze Pasargad Company (S.S.P. Co), Shiraz, Iran \\ SSP.ROBOTIC@gmail.com \\ Mohammad Reza Rashidian \\ Research and Development Unit, SanatkadeheSabze Pasargad Company (S.S.P. Co), Shiraz, Iran \\ SSP.ROBOTIC@gmail.com
}

\begin{abstract}
Refer to this paper, an intelligent-fuzzy feedforward computed torque estimator for ProportionalIntegral-Derivative (PID) controller is proposed for highly nonlinear continuum robot manipulator. In the absence of robot knowledge, PID may be the best controller, because it is model-free, and its parameters can be adjusted easily and separately and it is the most used in robot manipulators. In order to remove steadystate error caused by uncertainties and noise, the integrator gain has to be increased. This leads to worse transient performance, even destroys the stability. The integrator in a PID controller also reduces the bandwidth of the closed-loop system. Model-based compensation for PD control is an alternative method to substitute PID control. Computed torque compensation is one of the nonlinear compensator. The main problem of the pure computed torque compensator (CTC) was highly nonlinear dynamic parameters which related to system's dynamic parameters in certain and uncertain systems. The
\end{abstract}

nonlinear equivalent dynamic problem in uncertain system is solved by using feed-forward fuzzy inference system. To eliminate the continuum robot manipulator system's dynamic; Mamdani fuzzy inference system is design and applied to CTC. This methodology is based on design feed-forward fuzzy inference system and applied to CTC. The results demonstrate that the model base feed-forward fuzzy CTC estimator works well to compensate linear PID controller in presence of partly uncertainty system (e.g., continuum robot).

Index Terms - Fuzzy inference system, Mamdani fuzzy inference engine, computed torque estimator, continuum robot, linear PID theory

\section{INTRODUCTION}

Continuum robots represent a class of robots that have a biologically inspired form characterized by flexible 
backbones and high degrees-of-freedom structures [1]. The idea of creating "trunk and tentacle" robots, (in recent years termed continuum robots [1]), is not new [2]. Inspired by the bodies of animals such as snakes [3], the arms of octopi [4], and the trunks of elephants [5-6], researchers have been building prototypes for many years. A key motivation in this research has been to reproduce in robots some of the special qualities of the biological counterparts. This includes the ability to "slither" into tight and congested spaces, and (of particular interest in this work) the ability to grasp and manipulate a wide range of objects, via the use of "whole arm manipulation" i.e. wrapping their bodies around objects, conforming to their shape profiles. Hence, these robots have potential applications in whole arm grasping and manipulation in unstructured environments such as rescue operations. Theoretically, the compliant nature of a continuum robot provides infinite degrees of freedom to these devices. However, there is a limitation set by the practical inability to incorporate infinite actuators in the device. Most of these robots are consequently underactuated (in terms of numbers of independent actuators) with respect to their anticipated tasks. In other words they must achieve a wide range of configurations with relatively few control inputs. This is partly due to the desire to keep the body structures (which, unlike in conventional rigidlink manipulators or fingers, are required to directly contact the environment) "clean and soft", but also to exploit the extra control authority available due to the continuum contact conditions with a minimum number of actuators. For example, the Octarm VI continuum manipulator, discussed frequently in this paper, has nine independent actuated degrees-of-freedom with only three sections. Continuum manipulators differ fundamentally from rigid-link and hyper-redundant robots by having an unconventional structure that lacks links and joints. Hence, standard techniques like the Denavit-Hartenberg (D-H) algorithm cannot be directly applied for developing continuum arm kinematics. Moreover, the design of each continuum arm varies with respect to the flexible backbone present in the system, the positioning, type and number of actuators. The constraints imposed by these factors make the set of reachable configurations and nature of movements unique to every continuum robot. This makes it difficult to formulate generalized kinematic or dynamic models for continuum robot hardware. Chirikjian and Burdick were the first to introduce a method for modeling the kinematics of a continuum structure by representing the curve-shaping function using modal functions [6-15]. Mochiyama used the Serret- Frenet formulae to develop kinematics of hyperdegrees of freedom continuum manipulators [5]. For details on the previously developed and more manipulator-specific kinematics of the Rice/Clemson "Elephant trunk" manipulator, see [1-5]. For the Air Octor and Octarm continuum robots, more general forward and inverse kinematics have been developed by incorporating the transformations of each section of the manipulator (using D-H parameters of an equivalent virtual rigid link robot) and expressing those in terms of the continuum manipulator section parameters [4]. The net result of the work in [3-6] is the establishment of a general set of kinematic algorithms for continuum robots. Thus, the kinematics (i.e. geometry based modeling) of a quite general set of prototypes of continuum manipulators has been developed and basic control strategies now exist based on these. The development of analytical models to analyze continuum arm dynamics (i.e. physicsbased models involving forces in addition to geometry) is an active, ongoing research topic in this field. From a practical perspective, the modeling approaches currently available in the literature prove to be very complicated and a dynamic model which could be conveniently implemented in an actual device's real-time controller has not been developed yet. The absence of a computationally tractable dynamic model for these robots also prevents the study of interaction of external forces and the impact of collisions on these continuum structures. This impedes 
the study and ultimate usage of continuum robots in various practical applications like grasping and manipulation, where impulsive dynamics [1-4] are important factors. Although continuum robotics is an interesting subclass of robotics with promising applications for the future, from the current state of the literature, this field is still in its stages of inception [1620].

In the absence of robot knowledge, proportionalintegral-derivative (PID) may be the best controller, because it is model-free, and its parameters can be adjusted easily and separately [1]. And it is the most used in continuum robot manipulators. In order to remove steady-state error caused by uncertainties and noise, the integrator gain has to be increased. This leads to worse transient performance, even destroys the stability. The integrator in a PID controller also reduces the bandwidth of the closed-loop system. PD control guarantees stability only when the PD gains tend to infinity, the tracking error does not tend to zero when friction and gravity forces are included in the continuum robot manipulator dynamics [2]. Model-based compensation for PD control is an alternative method to substitute PID control [1], such as adaptive gravity compensation [3], desired gravity compensation [2], and PD+ with position measurement [4]. They all needed structure information of the robot gravity. Some nonlinear PD controllers can also achieve asymptotic stability, for example PD control with timevarying gains [5], PD control with nonlinear gains [6], and PD control with feedback linearization compensation [8]. But these controllers are complex, many good properties of the linear PID control do not exist because these controllers do not have the same form as the industrial PID. When the friction and gravity forces are unknown, both fuzzy logic and feedback linearization techniques can compensate them [9]. A fuzzy-adaptive controller by using a fuzzy inference engine plus a servo feedback control was proposed in [10]. A hybrid neuro control for robot tracking was discussed in [11-28], where static neural networks are used to learn mass matrix, centrifugal and Coriolis forces. Because they used the theory of function approximation, the algorithms are sensitive to the training data and local minima. Due to fuzzy modeling error, fuzzy controllers cannot assure that the regulation errors are asymptotically stable.

Computed torque compensator (CTC) is a powerful nonlinear estimator which it widely used in control of robot manipulator. It is based on feedback linearization and computes the required arm torques using the nonlinear feedback control law. This controller/estimator works very well when all dynamic and physical parameters are known but when the continuum robot manipulator has variation in dynamic parameters, the controller/estimator has no acceptable performance[7-14]. In practice, most of continuum robot manipulator systems parameters are unknown or time variant, therefore, feedforward artificial intelligence fuzzy computed torque estimator is used to compensate dynamic equation of continuum robot manipulator[1, 6]. Research on CTC is significantly growing on robot manipulator application which has been reported in $[1,6,15-20]$. When all dynamic and physical parameters are known, CTC works fantastically; practically a large amount of systems have uncertainties, therefore artificial intelligence (fuzzy inference system) methodology applied to CTC to estimate the nonlinear equivalent part based on parallel methodology.

Fuzzy-logic aims to provide an approximate but effective means of describing the behavior of systems that are not easy to describe precisely, and which are complex or ill-defined. It is based on the assumption that, in contrast to Boolean logic, a statement can be partially true (or false). For example, the expression (I live near SSP) where the fuzzy value (near) applied to the fuzzy 
variable (distance), in addition to being imprecise, is subject to interpretation. The essence of fuzzy control is to build a model of human expert who is capable of controlling the plant without thinking in terms of its mathematical model. As opposed to conventional control approaches where the focus is on constructing a controller described by differential equations, in fuzzy control the focus is on gaining an intuitive understanding (heuristic data) of how to best control the process, and then load this data into the control system [22-53]

This paper is organized as follows; section 2, is served as an introduction to the PID controller, computed torque compensator, Mamdani fuzzy inference engine to estimate the CTC and its application to control of continuum robot and dynamic of continuum robot. Part 3, introduces and describes the methodology. Section 4 presents the simulation results and discussion of this algorithm applied to a continuum robot and the final section is describing the conclusion.

\section{THEORY}

\section{A. Dynamic Formulation of Continuum Robot}

The Continuum section analytical model developed here consists of three modules stacked together in series. In general, the model will be a more precise replication of the behavior of a continuum arm with a greater of modules included in series. However, we will show that three modules effectively represent the dynamic behavior of the hardware, so more complex models are not motivated. Thus, the constant curvature bend exhibited by the section is incorporated inherently within the model. The mass of the arm is modeled as being concentrated at three points whose co-ordinates referenced with respect to (see Figure 1);

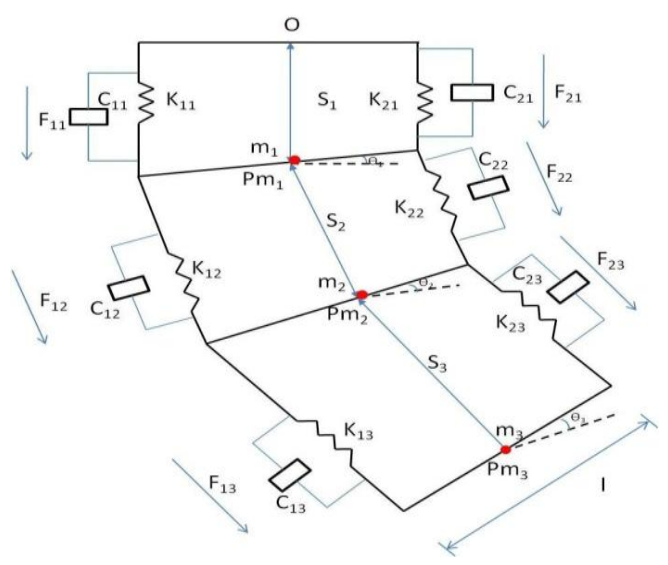

Figure 1: Assumed structure for analytical model of a section of a continuum arm

Where;

$l$ - Length of the rigid rod connecting the two struts, constant throughout the structure

$k_{1, i}, i=1,2,3$ - Spring constant of actuator 1 at module $i$

$k_{2, i}, i=1,2,3$ - Spring constant of actuator 2 at module $i$

$C_{1, i}, i=1,2,3$ - Damping coefficient of actuator 1 at module $i$

$C_{2, i}, i=1,2,3$ - Damping coefficient of actuator 2 at module $i$

$m_{i}, i=1,2,3$ - Mass in each module

$I_{i}, i=1,2,3$ - Moment of inertia of the rigid rod in each module.

A global inertial frame $(\mathrm{N})$ located at the base of the arm are given below

$$
\begin{aligned}
&{ }_{\mathrm{m} 1}^{\mathrm{N}} \mathrm{P}=\mathrm{S}_{1} \cdot \widehat{\mathrm{n}_{3}} \\
&{ }_{\mathrm{m} 2}^{\mathrm{N}} \mathrm{P}=\mathrm{S}_{2} \cdot \sin \theta_{1} \widehat{\mathrm{n}_{1}}+\left(\mathrm{S}_{1}+\mathrm{S}_{2} \cos \theta_{1}\right) \cdot \widehat{\mathrm{n}_{3}} \\
&\left.{ }_{\mathrm{m} 3 \mathrm{P}=\left(\mathrm{S}_{2} \cdot \sin \theta_{1}\right.}+\mathrm{S}_{3} \cdot \sin \left(\theta_{1}+\theta_{2}\right)\right) \widehat{\mathrm{n}_{1}} \\
&+\left(\mathrm{S}_{1}\right. \\
&+\mathrm{S}_{2} \cos \theta_{1} \\
&\left.\left.+\mathrm{S}_{3} \cdot \cos \left(\theta_{1}+\theta_{2}\right)\right)\right) \cdot \widehat{\mathrm{n}_{3}}
\end{aligned}
$$


The position vector of each mass is initially defined in a frame local to the module in which it is present. These local frames are located at the base of each module and oriented along the direction of variation of coordinate ' $s$ ' of that module. The positioning of each of these masses is at the centre of mass of the rigid rods connecting the two actuators. Differentiating the position vectors we obtain the linear velocities of the masses. The kinetic energy (T) of the system comprises the sum of linear kinetic energy terms (constructed using the above velocities) and rotational kinetic energy terms due to rotation of the rigid rod connecting the two actuators, and is given below as

$$
\begin{aligned}
& \mathrm{T}=(0.5) \mathrm{m}_{1} \dot{\mathrm{s}}_{1}{ }^{2}+(0.5) \mathrm{m}_{2}\left(\left(\dot{\mathrm{s}}_{2} \sin \theta_{1}+\right.\right. \\
& \left.\mathrm{s}_{2} \cos \theta_{1} \dot{\theta}_{1}\right)^{2}+ \\
& \left.\left(\dot{\mathrm{s}}_{1}+\dot{\mathrm{s}}_{2} \cos \theta_{1}-\mathrm{s}_{2} \sin \theta_{1} \dot{\theta}_{1}\right)^{2}\right)+ \\
& (0.5) \mathrm{m}_{3}\left(\left(\dot{\mathrm{s}}_{2} \sin \theta_{1}+\mathrm{s}_{2} \cos \theta_{1} \dot{\theta}_{1}+\right.\right. \\
& \dot{\mathrm{s}}_{3} \sin \left(\theta_{1}+\theta_{2}\right)+\mathrm{s}_{3} \cos \left(\theta_{1}+\theta_{2}\right) \dot{\theta}_{1}+ \\
& \left.\mathrm{s}_{3} \cos \left(\theta_{1}+\theta_{2}\right) \dot{\theta}_{2}\right)^{2}+\left(\dot{\mathrm{s}}_{1}+\dot{\mathrm{s}}_{2} \cos \theta_{1}-\right. \\
& \mathrm{s}_{2} \sin \theta_{1} \dot{\theta}_{1}+\dot{\mathrm{s}}_{3} \cos \left(\theta_{1}+\theta_{2}\right)-\mathrm{s}_{3} \sin \left(\theta_{1}+\right. \\
& \left.\left.\left.\theta_{2}\right) \dot{\theta}_{1}-\mathrm{s}_{3} \sin \left(\theta_{1}+\theta_{2}\right) \dot{\theta}_{2}\right)^{2}\right)+(0.5) \mathrm{I}_{1} \dot{\theta}_{1}{ }^{2}+ \\
& (0.5) \mathrm{I}_{2}\left(\dot{\theta}_{1}{ }^{2}+\dot{\theta}_{2}{ }^{2}\right)+(0.5) \mathrm{I}_{3}\left(\dot{\theta}_{1}{ }^{2}+\dot{\theta}_{2}{ }^{2}+\right. \\
& \left.\dot{\theta}_{3}{ }^{2}\right) .
\end{aligned}
$$

The potential energy $(\mathrm{P})$ of the system comprises the sum of the gravitational potential energy and the spring potential energy. A small angle assumption is made throughout the derivation. This allows us to directly express the displacement of springs and the velocities associated with dampers in terms of system generalized coordinates.

$$
\begin{aligned}
& \mathrm{P}=-\mathrm{m}_{1} g \mathrm{~s}_{1}-\mathrm{m}_{2} \mathrm{~g}\left(\mathrm{~s}_{1}+\mathrm{s}_{2} \cos \theta_{1}\right)- \\
& \mathrm{m}_{3} \mathrm{~g}\left(\mathrm{~s}_{1}+\mathrm{s}_{2} \cos \theta_{1}+\mathrm{s}_{3} \cos \left(\theta_{1}+\theta_{1}\right)\right)+ \\
& (0.5) \mathrm{k}_{11}\left(\mathrm{~s}_{1}+(1 / 2) \theta_{1}-\mathrm{s}_{01}\right)^{2}+ \\
& (0.5) \mathrm{k}_{21}\left(\mathrm{~s}_{1}+(1 / 2) \theta_{1}-\mathrm{s}_{01}\right)^{2}+ \\
& (0.5) \mathrm{k}_{12}\left(\mathrm{~s}_{2}+(1 / 2) \theta_{2}-\mathrm{s}_{02}\right)^{2}+ \\
& (0.5) \mathrm{k}_{22}\left(\mathrm{~s}_{2}+(1 / 2) \theta_{2}-\mathrm{s}_{02}\right)^{2}+ \\
& (0.5) \mathrm{k}_{13}\left(\mathrm{~s}_{3}+(1 / 2) \theta_{3}-\mathrm{s}_{03}\right)^{2}+ \\
& (0.5) \mathrm{k}_{23}\left(\mathrm{~s}_{3}+(1 / 2) \theta_{3}-\mathrm{s}_{03}\right)^{2}
\end{aligned}
$$

where, $S_{01}, S_{02}, S_{03}$ are the initial values of $S_{1}, S_{2}, S_{3}$ respectively.

Due to viscous damping in the system, Rayliegh's dissipation function [6] is used to give damping energy

$$
\begin{aligned}
& \mathrm{D}= \\
& (0.5) \mathrm{c}_{11}\left(\dot{\mathrm{s}}_{1}+(1 / 2) \dot{\theta}_{1}\right)^{2}+(0.5) \mathrm{c}_{21}\left(\dot{\mathrm{s}}_{1}+\right. \\
& \left.(1 / 2) \dot{\theta}_{1}\right)^{2}+(0.5) \mathrm{c}_{12}\left(\dot{\mathrm{s}}_{2}+(1 / 2) \dot{\theta}_{2}\right)^{2}+ \\
& (0.5) \mathrm{c}_{22}\left(\dot{\mathrm{s}}_{2}+(1 / 2) \dot{\theta}_{2}\right)^{2}+(0.5) \mathrm{c}_{13}\left(\dot{\mathrm{s}}_{3}+\right. \\
& \left.(1 / 2) \dot{\theta}_{3}\right)^{2}+(0.5) \mathrm{c}_{23}\left(\dot{\mathrm{s}}_{3}+(1 / 2) \dot{\theta}_{3}\right)^{2}
\end{aligned}
$$

The generalized forces in the system corresponding to the generalized co-ordinates are expressed as appropriately weighted combinations of the input forces.

$$
\begin{aligned}
& \mathrm{Q}_{\mathrm{s}_{1}}=\mathrm{F}_{11}+\mathrm{F}_{21}+\left(\mathrm{F}_{12}+\mathrm{F}_{22}\right) \cos \theta_{1}+ \\
& \left(\mathrm{F}_{13}+\mathrm{F}_{23}\right) \cos \left(\theta_{1}+\theta_{2}\right) \\
& \mathrm{Q}_{\mathrm{s}_{2}}=\mathrm{F}_{12}+\mathrm{F}_{22}+\left(\mathrm{F}_{13}+\mathrm{F}_{23}\right) \cos \left(\theta_{2}\right) \\
& \mathrm{Q}_{\mathrm{s}_{3}}=\mathrm{F}_{13}+\mathrm{F}_{23} \\
& \mathrm{Q}_{\theta_{1}}=(1 / 2)\left(\mathrm{F}_{11}-\mathrm{F}_{21}\right)+(1 / 2)\left(\mathrm{F}_{12}-\right. \\
& \left.\mathrm{F}_{22}\right)+(1 / 2)\left(\mathrm{F}_{13}-\mathrm{F}_{23}\right)+\mathrm{s}_{2} \sin \theta_{2}\left(\mathrm{~F}_{13}+\right. \\
& \left.\mathrm{F}_{23}\right) \\
& \mathrm{Q}_{\theta_{1}}=(1 / 2)\left(\mathrm{F}_{12}-\mathrm{F}_{22}\right) \\
& \quad+(1 / 2)\left(\mathrm{F}_{13}-\mathrm{F}_{23}\right) \\
& \mathrm{Q}_{\theta_{1}}=(1 / 2)\left(\mathrm{F}_{13}-\mathrm{F}_{23}\right)
\end{aligned}
$$

It can be evinced from the force expressions that the total input forces acting on each module can be resolved into an additive component along the direction of extension and a subtractive component that results in a torque. For the first module, there is an additional torque produced by forces in the third module.

The model resulting from the application of Lagrange's equations of motion obtained for this system can be represented in the form

$$
F_{\text {coeff }} \underline{\tau}=D(\underline{q}) \underline{\ddot{q}}+C(\underline{q}) \underline{\dot{q}}+G(\underline{q})
$$

where $\tau$ is a vector of input forces and $\mathrm{q}$ is a vector of generalized co-ordinates. The force coefficient matrix $F_{\text {coeff }}$ transforms the input forces to the generalized forces and torques in the system. The inertia matrix, $D$ is composed of four block matrices. The block matrices that correspond to pure linear accelerations and pure angular accelerations in the system (on the top left and on the bottom right) are symmetric. The matrix $C$ contains coefficients of the first order derivatives of the generalized co-ordinates. Since the system is nonlinear, many elements of $C$ contain first order derivatives of the 
generalized co-ordinates. The remaining terms in the dynamic equations resulting from gravitational potential energies and spring energies are collected in the matrix $G$. The coefficient matrices of the dynamic equations are given below,

$$
\begin{aligned}
& \text { Fcoeff }= \\
& {\left[\begin{array}{cccccc}
1 & 1 & \cos \left(\theta_{1}\right) & \cos \left(\theta_{1}\right) & \cos \left(\theta_{1}+\theta_{2}\right) & \cos \left(\theta_{1}+\theta_{2}\right) \\
0 & 0 & 1 & 1 & \cos \left(\theta_{2}\right) & \cos \left(\theta_{2}\right) \\
0 & 0 & 0 & 0 & 1 & 1 \\
1 / 2 & -1 / 2 & 1 / 2 & -1 / 2 & 1 / 2+s_{2} \sin \left(\theta_{2}\right) & -1 / 2+s_{2} \sin \left(\theta_{2}\right) \\
0 & 0 & 1 / 2 & -1 / 2 & 1 / 2 & -1 / 2 \\
0 & 0 & 0 & 0 & 1 / 2 & -1 / 2
\end{array}\right]} \\
& D(\underline{q})=
\end{aligned}
$$

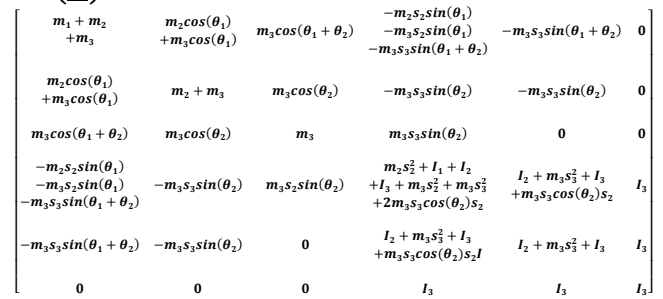

$$
\begin{aligned}
& C(\underline{q})=
\end{aligned}
$$

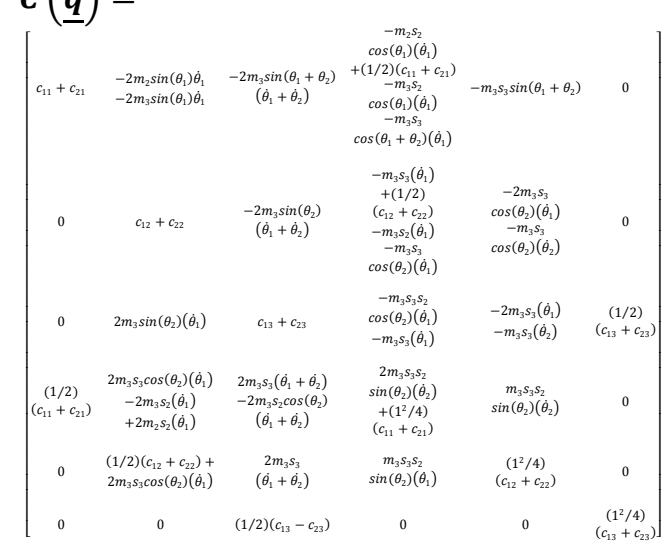

$$
\begin{aligned}
& \boldsymbol{G}(\underline{\boldsymbol{q}})= \\
& {\left[\begin{array}{c}
-m_{1} g-m_{2} g+k_{11}\left(s_{1}+(1 / 2) \theta_{1}-s_{01}\right)+k_{21}\left(s_{1}-(1 / 2) \theta_{1}-s_{01}\right)-m_{3} g \\
-m_{2} g \cos \left(\theta_{1}\right)+k_{12}\left(s_{2}+(1 / 2) \theta_{2}-s_{02}\right)+k_{22}\left(s_{2}-(1 / 2) \theta_{2}-s_{02}\right)-m_{3} g \cos \left(\theta_{1}\right) \\
-m_{3} g \cos \left(\theta_{1}+\theta_{2}\right)+k_{13}\left(s_{3}+(1 / 2) \theta_{3}-s_{03}\right)+k_{23}\left(s_{3}-(1 / 2) \theta_{3}-s_{03}\right) \\
m_{2} s_{2} g \sin \left(\theta_{1}\right)+m_{3} s_{3} g \sin \left(\theta_{1}+\theta_{2}\right)+m_{3} s_{2} g \sin \left(\theta_{1}\right)+k_{11}\left(s_{1}+(1 / 2) \theta_{1}-s_{01}\right)(1 / 2) \\
+k_{21}\left(s_{1}-(1 / 2) \theta_{1}-s_{01}\right)(-1 / 2) \\
m_{3} s_{3} g \sin \left(\theta_{1}+\theta_{2}\right)+k_{12}\left(s_{2}+(1 / 2) \theta_{2}-s_{02}\right)(1 / 2)+k_{22}\left(s_{2}-(1 / 2) \theta_{2}-s_{02}\right)(-1 / 2) \\
k_{13}\left(s_{3}+(1 / 2) \theta_{3}-s_{03}\right)(1 / 2)+k_{23}\left(s_{3}-(1 / 2) \theta_{3}-s_{03}\right)(-1 / 2)
\end{array}\right]}
\end{aligned}
$$

\section{B. Design PID Controller}

Design of a linear methodology to control of continuum robot manipulator was very straight forward. Since there was an output from the torque model, this means that there would be two inputs into the PID controller. Similarly, the outputs of the controller result from the two control inputs of the torque signal. In a typical PID method, the controller corrects the error between the desired input value and the measured value. Since the actual position is the measured signal. Figure 2 is shown linear PID methodology, applied to continuum robot manipulator [21-34].

$$
\begin{aligned}
& \mathrm{e}(\mathrm{t})=\theta_{\mathrm{a}}(\mathrm{t})-\theta_{\mathrm{d}}(\mathrm{t}) \\
& \mathrm{U}_{\mathrm{PID}}=\mathrm{K}_{\mathrm{p}_{\mathrm{a}}} \mathrm{e}+\mathrm{K}_{\mathrm{V}_{\mathrm{a}}} \dot{\mathrm{e}}+\mathrm{K}_{\mathrm{I}} \sum \mathrm{e}
\end{aligned}
$$

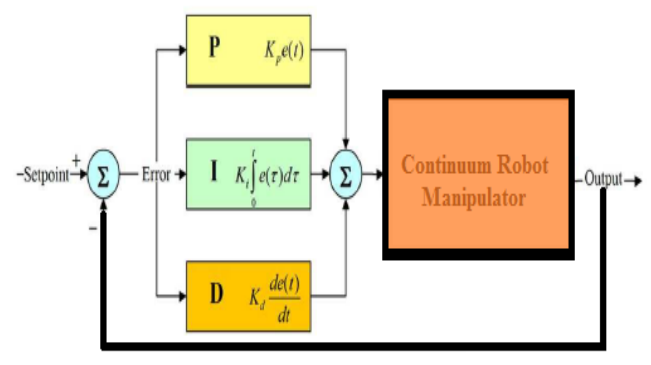

Figure 2: Block diagram of linear PD method

The model-free control strategy is based on the assumption that the joints of the manipulators are all independent and the system can be decoupled into a group of single-axis control systems [18-23]. Therefore, the kinematic control method always results in a group of individual controllers, each for an active joint of the manipulator. With the independent joint assumption, no a priori knowledge of robot manipulator dynamics is needed in the kinematic controller design, so the complex computation of its dynamics can be avoided and the controller design can be greatly simplified. This is suitable for real-time control applications when powerful processors, which can execute complex algorithms rapidly, are not accessible. However, since joints coupling is neglected, control performance degrades as operating speed increases and a manipulator controlled in this way is only appropriate for relatively slow motion $[44,46]$. The fast motion requirement results in even higher dynamic coupling between the various robot joints, which cannot be compensated for by a standard robot controller such as PID [50], and hence model-based control becomes the alternative. 


\section{Computed Torque Compensator}

The central idea of computed torque compensator (CTC) is feedback linearization methodology. It has assumed that the desired motion trajectory for the continuum robot manipulator $\boldsymbol{q}_{\boldsymbol{d}}(\boldsymbol{t})$, as determined, by a path planner. Defines the tracking error as:

$$
\mathrm{e}(\mathrm{t})=\mathrm{q}_{\mathrm{d}}(\mathrm{t})-\mathrm{q}_{\mathrm{a}}(\mathrm{t})
$$

Where e(t) is error of the plant, $\boldsymbol{q}_{\boldsymbol{d}}(\boldsymbol{t})$ is desired input variable, that in our system is desired displacement, $\boldsymbol{q}_{\boldsymbol{a}}(\boldsymbol{t})$ is actual displacement. If an alternative linear statespace equation in the form $\dot{\boldsymbol{x}}=\boldsymbol{A} \boldsymbol{x}+\boldsymbol{B} \boldsymbol{U}$ can be defined as

$$
\dot{\mathrm{x}}=\left[\begin{array}{ll}
0 & \mathrm{I} \\
0 & 0
\end{array}\right] \mathrm{x}+\left[\begin{array}{l}
0 \\
\mathrm{I}
\end{array}\right] \mathrm{U}
$$

With $\boldsymbol{U}=-D^{-1}(\boldsymbol{q}) \cdot \boldsymbol{N}(\boldsymbol{q}, \dot{\boldsymbol{q}})+\boldsymbol{D}^{-\mathbf{1}}(\boldsymbol{q}) \cdot \boldsymbol{\tau}$ and this is known as the Brunousky canonical form. By equation (18) and (19) the Brunousky canonical form can be written in terms of the state $\boldsymbol{x}=\left[\boldsymbol{e}^{T} \dot{e}^{T}\right]^{T}$ as [35-44]:

$$
\frac{\mathrm{d}}{\mathrm{dt}}\left[\begin{array}{l}
\mathrm{e} \\
\dot{\mathrm{e}}
\end{array}\right]=\left[\begin{array}{ll}
0 & \mathrm{I} \\
0 & 0
\end{array}\right] \cdot\left[\begin{array}{l}
\mathrm{e} \\
\dot{\mathrm{e}}
\end{array}\right]+\left[\begin{array}{l}
0 \\
\mathrm{I}
\end{array}\right] \mathrm{U}
$$

With

$$
U=\ddot{q}_{d}+D^{-1}(q) \cdot\{N(q \cdot \dot{q})-\tau\}
$$

Then compute the required arm torques using inverse of equation (23), is;

$$
\tau=D(q)\left(\ddot{q_{d}}-U\right)+N(\dot{q}, q)
$$

This is a nonlinear feedback control law that guarantees tracking of desired trajectory. Selecting proportional-plus-derivative (PD) feedback for $\mathrm{U}(\mathrm{t})$ results in the $\mathrm{PD}$-computed torque compensator [45-53];

$$
\tau=\mathrm{D}(\mathrm{q})\left(\ddot{\mathrm{q}}_{\mathrm{d}}+\mathrm{K}_{\mathrm{v}} \dot{\mathrm{e}}+\mathrm{K}_{\mathrm{p}} \mathrm{e}\right)+\mathrm{N}(\mathrm{q}, \dot{\mathrm{q}})
$$

and the resulting linear error dynamics are

$$
\left(\ddot{\mathrm{q}}_{\mathrm{d}}+\mathrm{K}_{\mathrm{v}} \dot{\mathrm{e}}+\mathrm{K}_{\mathrm{p}} \mathrm{e}\right)=0
$$

According to the linear system theory, convergence of the tracking error to zero is guaranteed [6]. Where $\boldsymbol{K}_{\boldsymbol{p}}$ and $\boldsymbol{K}_{\boldsymbol{v}}$ are the controller gains. The result schemes is shown in Figure 3, in which two feedback loops, namely, inner loop and outer loop, which an inner loop is a compensate loop and an outer loop is a tracking error loop.

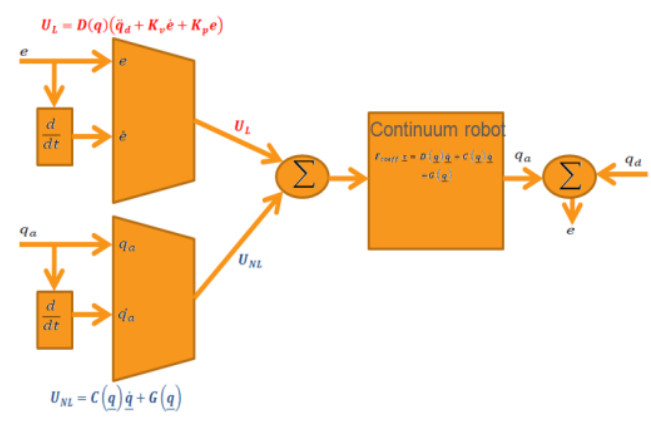

Figure 3: Block diagram of PD-computed torque compensator

(PD-CTC)

\section{Fuzzy Inference Engine:}

This section provides a review about foundation of fuzzy logic based on $[32,53]$. Supposed that $U$ is the universe of discourse and $x$ is the element of $U$, therefore, a crisp set can be defined as a set which consists of different elements $(x)$ will all or no membership in a set. A fuzzy set is a set that each element has a membership grade, therefore it can be written by the following definition;

$$
\mathrm{A}=\left\{\mathrm{X}, \mu_{\mathrm{A}}(\mathrm{x}) \mid \mathrm{x} \in \mathrm{X}\right\} ; \mathrm{A} \in \mathrm{U}
$$

Where an element of universe of discourse is $x, \mu_{A}$ is the membership function (MF) of fuzzy set. The membership function $\left(\mu_{A}(x)\right)$ of fuzzy set $A$ must have a value between zero and one. If the membership function $\mu_{A}(x)$ value equal to zero or one, this set change to a crisp set but if it has a value between zero and one, it is a fuzzy set. Defining membership function for fuzzy sets has divided into two main groups; namely; numerical and functional method, which in numerical method each number has different degrees of membership function and functional method used standard functions in fuzzy sets. The membership function which is often used in practical applications includes triangular form, trapezoidal form, bell-shaped form, and Gaussian form.

Linguistic variable can open a wide area to use of fuzzy logic theory in many applications (e.g., control and system identification). In a natural artificial language all numbers replaced by words or sentences. 
If - then Rule statements are used to formulate the condition statements in fuzzy logic. A single fuzzy

If - then rule can be written by

If $\mathrm{x}$ is $\mathrm{A}$ Then $\mathrm{y}$ is $\mathrm{B}$

where $A$ and $B$ are the Linguistic values that can be defined by fuzzy set, the If - part of the part of " $x$ is $A$ " is called the antecedent part and the then - part of the part of " $y$ is $B$ " is called the Consequent or Conclusion part. The antecedent of a fuzzy if-then rule can have multiple parts, which the following rules shows the multiple antecedent rules:

if $\mathrm{e}$ is $\mathrm{NB}$ and $\mathrm{e}$ is ML then T is $L L$

Where e is error, è is change of error, NB is Negative Big, ML is Medium Left, T is torque and LL is Large Left. If - then rules have three parts, namely, fuzzify inputs, apply fuzzy operator and apply implication method which in fuzzify inputs the fuzzy statements in the antecedent replaced by the degree of membership, apply fuzzy operator used when the antecedent has multiple parts and replaced by single number between 0 to 1 , this part is a degree of support for the fuzzy rule, and apply implication method used in consequent of fuzzy rule to replaced by the degree of membership. The fuzzy inference engine offers a mechanism for transferring the rule base in fuzzy set which it is divided into two most important methods, namely, Mamdani method and Sugeno method. Mamdani method is one of the common fuzzy inference systems and he designed one of the first fuzzy controllers to control of system engine. Mamdani’s fuzzy inference system is divided into four major steps: fuzzification, rule evaluation, aggregation of the rule outputs and defuzzification. Michio Sugeno use a singleton as a membership function of the rule consequent part. The following definition shows the Mamdani and Sugeno fuzzy rule base

$$
\begin{gathered}
\text { Mamdani } F \cdot R^{1} \text { if } \quad x \text { is } A \text { and } \\
y \text { is } B \text { then } \quad z \text { is } C \\
\text { Sugeno } \quad F . R^{1} \text { :if } \quad x \text { is } A \text { and } \\
y \text { is } B \text { then } f(x, y) \text { is } C
\end{gathered}
$$

When $x$ and $y$ have crisp values fuzzification calculates the membership degrees for antecedent part. Rule evaluation focuses on fuzzy operation $(A N D / O R)$ in the antecedent of the fuzzy rules. The aggregation is used to calculate the output fuzzy set and several methodologies can be used in fuzzy logic controller aggregation, namely, Max-Min aggregation, Sum-Min aggregation, Max-bounded product, Max-drastic product, Max-bounded sum, Max-algebraic sum and Min-max. Two most common methods that used in fuzzy logic controllers are Max-min aggregation and Sum-min aggregation. Max-min aggregation defined as below

$$
\begin{aligned}
& \mu_{U}\left(x_{k}, y_{k}, U\right)=\mu_{U_{i=1}^{r} F R^{i}}\left(x_{k}, y_{k}, U\right) \\
& =\max \left\{\min _{i=1}^{r}\left[\mu_{R_{p q}}\left(x_{k}, y_{k}\right), \mu_{p_{m}}(U)\right]\right\}
\end{aligned}
$$

The Sum-min aggregation defined as below

$$
\begin{aligned}
& \mu_{U}\left(x_{k}, y_{k}, U\right)=\mu_{U_{i=1}^{r} F R^{i}}\left(x_{k}, y_{k}, U\right) \\
& =\sum \min _{i=1}^{r}\left[\mu_{R_{p q}}\left(x_{k}, y_{k}\right), \mu_{p_{m}}(U)\right]
\end{aligned}
$$

where $r$ is the number of fuzzy rules activated by $x_{k}$ and $y_{k}$ and also $\mu_{\cup_{i=1}^{r} F R^{i}}\left(x_{k}, y_{k}, U\right)$ is a fuzzy interpretation of $i-t h$ rule. Defuzzification is the last step in the fuzzy inference system which it is used to transform fuzzy set to crisp set. Consequently defuzzification's input is the aggregate output and the defuzzification's output is a crisp number. Centre of gravity method ( $C O G)$ and Centre of area method (COA) are two most common defuzzification methods, which $C O G$ method used the following equation to calculate the defuzzification

$$
\operatorname{COG}\left(\mathrm{x}_{\mathrm{k}}, \mathrm{y}_{\mathrm{k}}\right)=\frac{\sum_{\mathrm{i}} \mathrm{U}_{\mathrm{i}} \sum_{\mathrm{j}=1}^{\mathrm{r}} \cdot \mu_{\mathrm{u}}\left(\mathrm{x}_{\mathrm{k}}, \mathrm{y}_{\mathrm{k}}, \mathrm{U}_{\mathrm{i}}\right)}{\sum_{\mathrm{i}} \sum_{\mathrm{j}=1}^{\mathrm{r}} \cdot \mu_{\mathrm{u}}\left(\mathrm{x}_{\mathrm{k}}, \mathrm{y}_{\mathrm{k}}, \mathrm{U}_{\mathrm{i}}\right)}
$$

and $C O A$ method used the following equation to calculate the defuzzification

$$
\operatorname{COA}\left(\mathrm{x}_{\mathrm{k}}, \mathrm{y}_{\mathrm{k}}\right)=\frac{\sum_{\mathrm{i}} \mathrm{U}_{\mathrm{i}} \cdot \mu_{\mathrm{u}}\left(\mathrm{x}_{\mathrm{k}}, \mathrm{y}_{\mathrm{k}}, \mathrm{U}_{\mathrm{i}}\right)}{\sum_{\mathrm{i}} \mu_{\mathrm{U}} \cdot\left(\mathrm{x}_{\mathrm{k}}, \mathrm{y}_{\mathrm{k}}, \mathrm{U}_{\mathrm{i}}\right)}
$$

Where $\operatorname{COG}\left(x_{k}, y_{k}\right)$ and $\operatorname{COA}\left(x_{k}, y_{k}\right)$ illustrates the crisp value of defuzzification output, $U_{i} \in U$ is discrete element of an output of the fuzzy set, $\mu_{U} \cdot\left(x_{k}, y_{k}, U_{i}\right)$ is the fuzzy set membership function, and $r$ is the number of fuzzy rules. 
Based on foundation of fuzzy logic methodology; fuzzy logic controller has played important rule to design nonlinear controller for nonlinear and uncertain systems [53]. However the application area for fuzzy control is really wide, the basic form for all command types of controllers consists of;

- Input fuzzification (binary-to-fuzzy[B/F]conversion)

- $\quad$ Fuzzy rule base (knowledge base)

- Inference engine

- Output defuzzification

(fuzzy-tobinary[F/B]conversion). Figure 4 shows the block diagram of fuzzy inference engine.

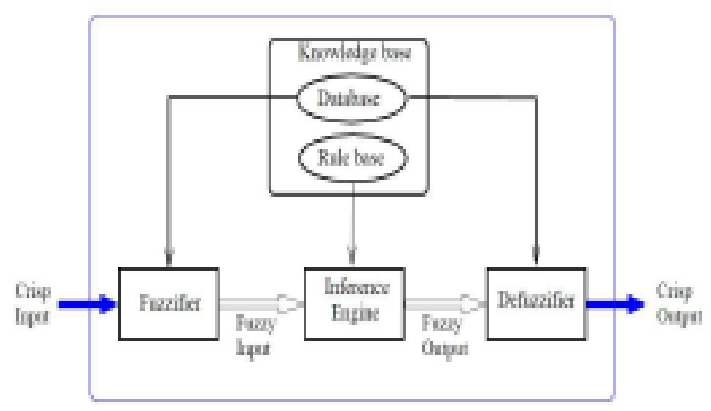

Figure 4: Block diagram of fuzzy inference engine

\section{METHODOLOGY}

Based on the dynamic formulation of continuum robot manipulator, (3), and the industrial PID law (5) in this paper we discuss about regulation problem, the desired position is constant, i.e., $\dot{q}_{d}=0$. In most continuum robot manipulator control, desired joint positions are generated by the trajectory planning. The objective of continuum robot control is to design the input torque in (1) such that the tracking error

$$
e=q_{d}-q_{a}
$$

When the dynamic parameters of robot formulation known, the PID control formulation (25) should include a compensator as

$$
\tau=-\mathrm{k}_{\mathrm{p}} \mathrm{e}-\mathrm{k}_{\mathrm{d}} \mathrm{e}-\mathrm{K}_{\mathrm{i}} \sum \mathrm{e}+(\mathrm{G}+\mathrm{F})
$$

Where $G$ is gravity and $F$ is appositive definite diagonal matrix friction term (coulomb friction). If we use a Lyapunov function candidate as

$$
\begin{aligned}
& \mathrm{V}_{\text {pid }}=\frac{1}{2} \dot{\mathrm{q}}^{\mathrm{T}} \mathrm{M} \dot{\mathrm{q}}+\frac{1}{2} \mathrm{e}^{\mathrm{T}} \mathrm{k}_{\mathrm{p}} \mathrm{e} \\
& \dot{\mathrm{V}}_{\text {pid }}=-\dot{\mathrm{q}}^{\mathrm{T}} \mathrm{k}_{\mathrm{d}} \dot{\mathrm{q}} \leq 0
\end{aligned}
$$

It is easy to known $\dot{\boldsymbol{q}}=\mathbf{0}$ and $\boldsymbol{e}=\mathbf{0}$ are only initial conditions in $\Omega=\{[\dot{\boldsymbol{q}}, \boldsymbol{e}]: \dot{\boldsymbol{V}}=\mathbf{0}\}$, for which $[\dot{\boldsymbol{q}}, \boldsymbol{e}] \in \Omega$ for al $1 \boldsymbol{t} \leq \mathbf{0}$. By the LaSalle's invariance principle, $\boldsymbol{e} \rightarrow \mathbf{0}$ and $\dot{\boldsymbol{e}} \rightarrow \mathbf{0}$. For PID controller application the system performances are sensitive to the controller coefficients $\left(\boldsymbol{K}_{\boldsymbol{p}}, \boldsymbol{K}_{\boldsymbol{v}}\right.$ and $\left.\boldsymbol{K}_{\boldsymbol{i}}\right)$. Therefore to have a good response, compute the best value controller coefficients are very important. Gradient descent algorithm is based on improving the input parameters by moving iteratively in the direction of the estimated gradient of the response of interest. One of the major concerns with this type of algorithm is the estimation of the gradient and its statistical properties. Naturally, the heart of gradient based algorithms is the technique used to estimate the gradient. Here we present the most common methods used in the simulation optimization literature. Gradient descent is based on the observation that if the multivariable function $\boldsymbol{F}(\boldsymbol{x})$ is defined and differentiable in a neighborhood of a point $\boldsymbol{a}$, then $\boldsymbol{F}(\boldsymbol{x})$ decreases fastest if one goes from $\boldsymbol{a}$ in the direction of the negative gradient of $\boldsymbol{F}$ at, $\boldsymbol{a}-\boldsymbol{\nabla} \boldsymbol{F}(\boldsymbol{a})$. It follows that, if

$$
\mathrm{b}=\mathrm{a}-\gamma \nabla \mathrm{F}(\mathrm{a})
$$

for $\gamma \rightarrow 0$ a small enough number, then $F(a)<F(b)$. With this observation in mind, one starts with a guess $x_{0}$ for a local minimum of $F$, and considers the sequence $x_{0}, x_{1}, x_{2}, \ldots .$. such that

$$
\mathrm{X}_{\mathrm{n}+1}=\mathrm{X}_{\mathrm{n}}-\gamma_{\mathrm{n}} \nabla \mathrm{F}\left(\mathrm{X}_{\mathrm{n}}\right), \quad \mathrm{n} \geq 0
$$

We have

$$
F\left(X_{0}\right) \geq F\left(X_{1}\right) \geq F\left(X_{2}\right), \geq \cdots
$$

So hopefully the sequence $\left(X_{n}\right)$ converges to the desired local minimum. Note that the value of the step size $\gamma$ is allowed to change at every iteration. With certain assumptions on the function $F$ (for example, $F$ convex and $\nabla F$ Lipschitz) and particular choices of $\gamma($ e.g., chosen via a line search that satisfies the Wolfe conditions), convergence to a local minimum can be guaranteed. 
When the function $F$ is convex, all local minima are also global minima, so in this case gradient descent can converge to the global solution. Figure 5 shows the block diagram of gradient descent PID controller.

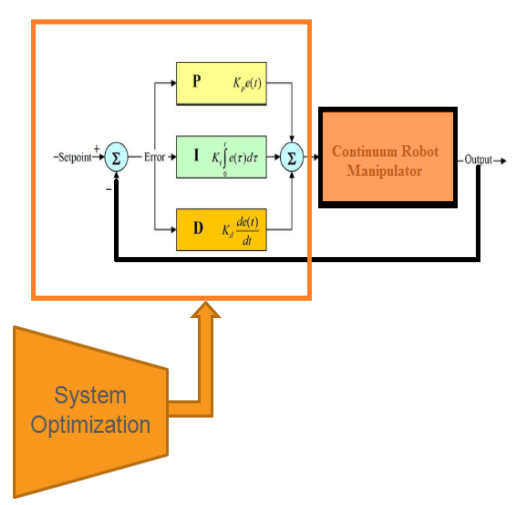

Figure 5: Block diagram of PID gradient descent optimization

When $G$ and $F$ in (25) are unknown, a fuzzy logic can be used to approximate them as

$$
f(x)=\sum_{l=1}^{M} \theta^{l} \mathcal{E}^{\mathrm{l}}(x)=\theta^{\mathrm{T}} \mathcal{E}(\mathrm{x})
$$

Where

$\theta=\left(\theta^{1}, \ldots, \theta^{M}\right)^{T}, \mathcal{E}(x)=$ $\left(\mathcal{E}^{1}(x), \ldots, \mathcal{E}^{M}(x)\right)^{T}$, and $\mathcal{E}^{l}(x)=$

$: \prod_{i=1}^{n} \frac{{ }_{A_{i}^{l}\left(x_{i}\right)}}{\sum_{l=1}^{M}}\left(\prod_{i=1}^{n} \mu_{A_{i}^{l}}\left(x_{i}\right)\right) \cdot \theta^{1}, \ldots, \theta^{M}$ are adjustable parameters in (41). $\mu_{A_{1}^{1}}\left(x_{1}\right), \ldots, \mu_{A_{n}^{m}}\left(x_{n}\right)$ are given membership functions whose parameters will not change over time.

The second type of fuzzy systems is given by

$$
\mathrm{f}(\mathrm{x})=\frac{\sum_{\mathrm{l}=1}^{\mathrm{M}} \theta^{\mathrm{l}}\left[\prod_{\mathrm{i}=1}^{\mathrm{n}} \exp \left(-\left(\frac{\mathrm{x}_{\mathrm{i}}-\alpha_{\mathrm{i}}^{\mathrm{l}}}{\delta_{\mathrm{i}}^{\mathrm{l}}}\right)^{2}\right)\right]}{\sum_{\mathrm{l}=1}^{\mathrm{M}}\left[\prod_{\mathrm{i}=1}^{\mathrm{n}} \exp \left(-\left(\frac{\mathrm{x}_{\mathrm{i}}-\alpha_{\mathrm{i}}^{\mathrm{l}}}{\delta_{\mathrm{i}}^{\mathrm{l}}}\right)^{2}\right)\right]}
$$

Where $\theta^{l}, \alpha_{i}^{l}$ and $\delta_{i}^{l}$ are all adjustable parameters. As mentioned in above, the design of error-based fuzzy based on Mamdani's fuzzy inference method has four steps , namely, fuzzification, fuzzy rule base and rule evaluation, aggregation of the rule output (fuzzy inference system) and defuzzification.
Fuzzification: the first step in fuzzification is determine inputs and outputs which, it has one input $\left(U_{C T C}\right)$ and one output $\left(U_{f u z z y}\right)$. The second step is chosen an appropriate membership function for input and output which, to simplicity in implementation because it is a linear function with regard to acceptable performance triangular membership function is selected in this research. The third step is chosen the correct labels for each fuzzy set which, in this research namely as linguistic variable. Based on experience knowledge the linguistic variables for $U_{C T C}$ are; Negative Big (NB), Negative Medium (NM), Negative Small (NS), Zero (Z), Positive Small (PS), Positive Medium (PM), Positive Big (PB), and based on literature [40] and experience knowledge it is quantized into thirteen levels represented by: $-1,-0.83$, $-0.66,-0.5,-0.33,-0.16,0,0.16,0.33,0.5,0.66,0.83,1$ and the linguistic variables to find the output are; Large Left (LL), Medium Left (ML), Small Left (SL), Zero (Z), Small Right (SR), Medium Right (MR), Large Right (LR) and it is quantized in to thirteen levels represented by: -85 , $-70.8,-56.7,-42.5,-28.3,-14.2,0,14.2,28.3,42.5,56.7$, $70.8,85$.

Fuzzy rule base and rule evaluation: the first step in rule base and evaluation is to provide a least structured method to derive the fuzzy rule base which, expert experience and control engineering knowledge is used because this method is the least structure of the other one and the researcher derivation the fuzzy rule base from the knowledge of system operate and/or the classical controller. Design the rule base of fuzzy inference system can play important role to design the best performance of fuzzy sliding mode controller, that to calculate the fuzzy rule base the researcher is used to heuristic method which, it is based on the behavior of the control of robot manipulator suppose that two fuzzy rules in this controller are;

$$
\begin{aligned}
& \text { F. }{ }^{1}: \text { IF } U_{\text {CTC }} \text { is NB, THEN } U \text { is } L L . \\
& \text { F. } \mathrm{R}^{2}: \text { IF } U_{\text {CTC }} \text { is PS THEN } U \text { is } S R
\end{aligned}
$$


Rule evaluation focuses on operation in the antecedent of the fuzzy rules in fuzzy inference compensator controller. Aggregation of the rule output (Fuzzy inference): based on (31), Max-Min aggregation is used in this work.

Defuzzification: The last step to design fuzzy inference in our fuzzy sliding mode controller is defuzzification. This part is used to transform fuzzy set to crisp set, therefore the input for defuzzification is the aggregate output and the output of it is a crisp number. Based on 33 Center of gravity method (COG) is used in this research. Figure 6 shows the fuzzy estimator for PID controller.

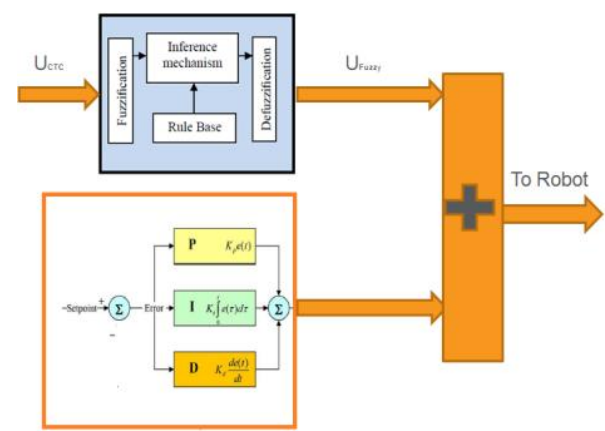

Figure 6: Block diagram of fuzzy compensator

We used the first type of fuzzy systems (42) to estimate the nonlinear system (26) the fuzzy formulation can be write as below;

$$
\begin{aligned}
\mathrm{f}(\mathrm{x} \mid \theta) & =\theta^{\mathrm{T}} \varepsilon(\mathrm{x}) \\
& =\frac{\sum_{\mathrm{l}=1}^{\mathrm{n}} \theta^{\mathrm{l}}\left[\mu_{\mathrm{A}^{\mathrm{l}}}(\mathrm{x})\right]}{\sum_{\mathrm{l}=1}^{\mathrm{n}}\left[\mu_{\mathrm{A}^{\mathrm{l}}}(\mathrm{x})\right]}
\end{aligned}
$$

Where $\theta^{1}, \ldots, \theta^{n}$ are adjusted by an adaptation law.

This method has two main controller's coefficients, $K_{p}$ and $K_{V}$. To tune and optimize these parameters mathematical formulation is used

$$
\begin{aligned}
& \mathrm{U}=\left[\left(\mathrm{U}_{\mathrm{NL}}+\mathrm{U}_{\text {lin }}\right) \times \mathrm{U}_{\mathrm{FUZZY}}\right]+\mathrm{U}_{\mathrm{PID}} \\
& \mathrm{U}=\left[\left(\mathrm{U}_{\mathrm{NL}}+\mathrm{U}_{\mathrm{lin}}\right) \times \mathrm{U}_{\mathrm{FUZZY}}\right]+\mathrm{U}_{\mathrm{PID}}= \\
& {[\mathrm{D}(\mathrm{C}+\mathrm{G})]+\mathrm{D}(\mathrm{q})\left(\ddot{\mathrm{q}}_{\mathrm{d}}+\mathrm{K}_{\mathrm{v}} \dot{\mathrm{e}}+\mathrm{K}_{\mathrm{p}} \mathrm{e}\right) \times} \\
& \frac{\sum_{\mathrm{l}=1}^{\mathrm{M}} \theta^{1}\left[\Pi_{\mathrm{i}=1}^{\mathrm{n}} \exp \left(-\left(\frac{\mathrm{x}_{\mathrm{i}}-\alpha_{\mathrm{i}}^{\mathrm{l}}}{\delta_{\mathrm{i}}^{l}}\right)^{2}\right)\right]}{\sum_{\mathrm{l}=1}^{\mathrm{M}}\left[\Pi_{\mathrm{i}=1}^{\mathrm{n}} \exp \left(-\left(\frac{\mathrm{x}_{\mathrm{i}}-\alpha_{\mathrm{i}}^{\mathrm{l}}}{\delta_{\mathrm{i}}^{\mathrm{l}}}\right)^{2}\right)\right]}+\left(\mathrm{K}_{\mathrm{p}_{\mathrm{a}}} \mathrm{e}+\right. \\
& \left.\mathrm{K}_{\mathrm{V}_{\mathrm{a}}} \dot{\mathrm{e}}+\mathrm{K}_{\mathrm{I}} \sum \mathrm{e}\right)
\end{aligned}
$$

The most important different between PID and PID+CTC $\times$ fuzzy inference system is in the uncertainty systems. In $P I D$ controller the uncertainty is $d=G+F+f$. The feedback linearization gain must be bigger than its upper bound. It is not an easy job because this term includes tracking errors $e_{1}$ and $\dot{q}_{1}$. While in PID+CTC $\times$ fuzzy inference system, the uncertainty $\eta$ is the fuzzy approximation error for $G+F+f$. Figure 7 shows the new methodology applied to continuum robot.

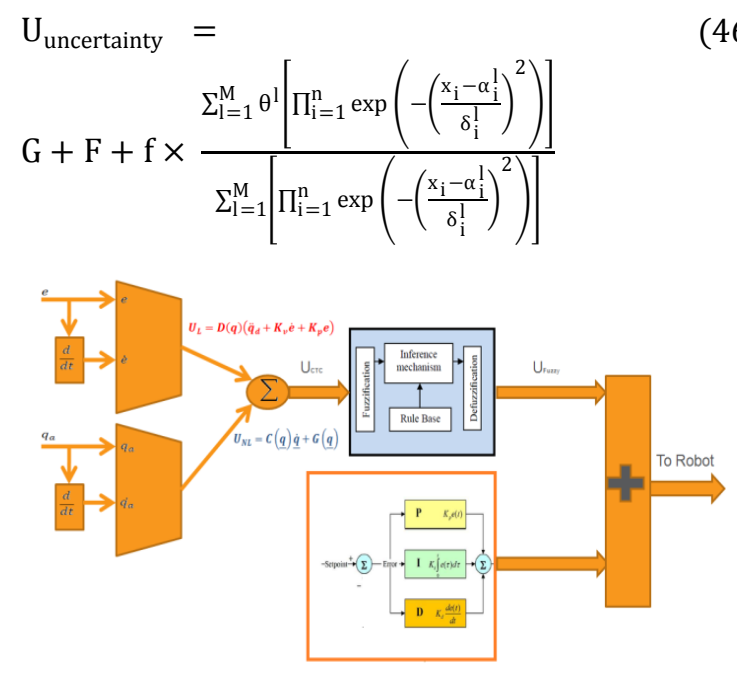

Figure 7: PID with computed torque fuzzy compensator

\section{RESULTS AND DISCUSSION}

Linear PID controller (PID), PID plus fuzzy controller and proposed computed torque fuzzy compensate PID controller were tested to ramp response trajectory. The simulation was implemented in MATLAB/SIMULINK environment. Position trajectory, disturbance rejection and error tracking are compared in these controllers.

Position trajectory: Figure 8 shows the links trajectory in PID controller, PID + fuzzy control and proposed computed torque fuzzy compensate PID controller without disturbance for ramp trajectory in general and zoom scaling. 

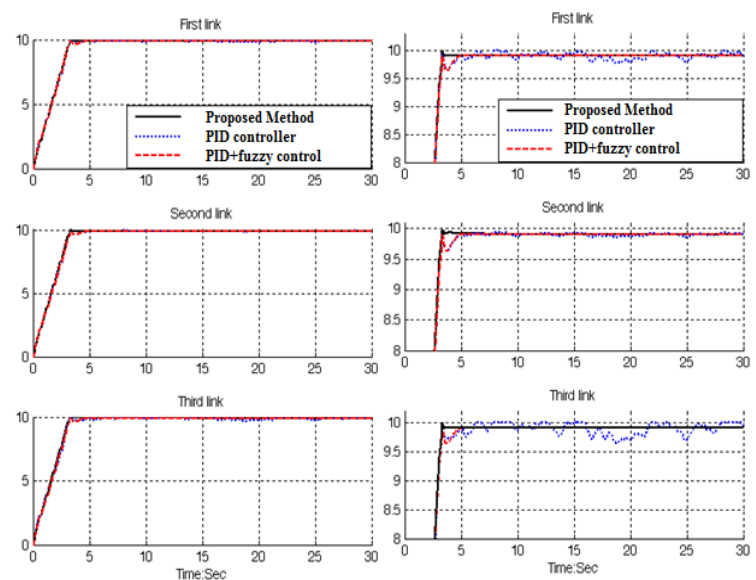

Figure 8: PID controller, PID+Fuzzy controller and proposed method

By comparing sinus response, Figure 8 , in PID controller, PID plus fuzzy control and proposed computed torque fuzzy compensate PID controller, we can seen the the proposed controller's overshoot $(\mathbf{0 \%})$ is lower than PID's (6.8\%) and fuzzy plus PID's (3.9\%).

Disturbance rejection: Figure 9 is indicated the power disturbance removal in PID controller, PID plus fuzzy control and proposed computed torque fuzzy compensate PID controller. Besides a band limited white noise with predefined of $30 \%$ the power of input signal is applied to the ramp PID controller, PID plus fuzzy controller and proposed computed torque fuzzy compensate PID controller; it found slight oscillations in PID position responses and PID plus fuzzy controller.
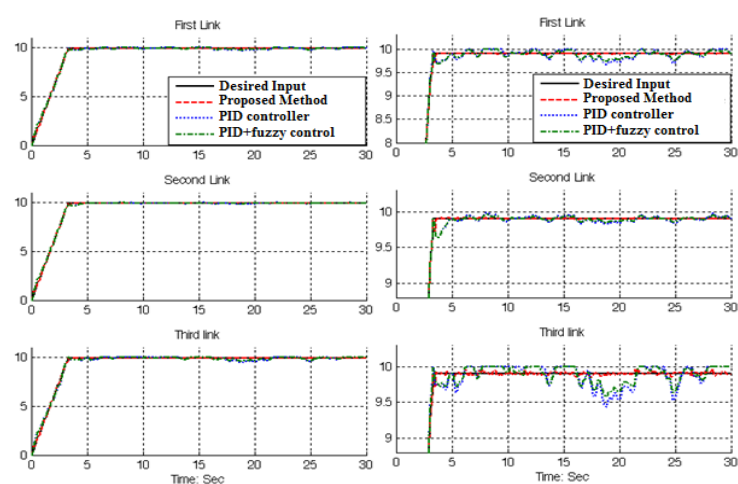

Figure 9: PID, PID plus fuzzy control and Proposed method:

Continuum robot arm with external disturbance

Among above graph, relating to ramp trajectory following with external disturbance, PID controller and
PID plus fuzzy control has slightly fluctuations. By comparing overshoot; proposed controller's overshoot $\mathbf{2 . 3 \%}$ ) is lower than PID's (16\%) and PID plus fuzzy's $(8 \%)$.

\section{CONCLUSION}

Refer to the research, proposed computed torques fuzzy compensates PID controller is designed and applied to continuum robot manipulator to design a controller based on the best quality. Based on this method, PID controller is the main controller and in the first part fuzzy controller is used to estimate the external disturbance. Regarding to the positive points in linear PID controller, serial computed torque compensator and fuzzy inference system it is found that this system can improve the stability and the trajectory performance. The main target in this work is design and implements the highly nonlinear model uncertainty by fuzzy feed-forward inference engine, in the case of continuum robot arm. In finally serial feed-forward fuzzy computed torque compensator is used to compensate and adjusted the linear PID controller. In this case the performance is improved by using the advantages of computed torque method and artificial intelligence compensate while the disadvantages removed by added each method to previous method.

\section{ACKNOWLEDGMENT}

The authors would like to thank the anonymous reviewers for their careful reading of this paper and for their helpful comments. This work was supported by the SSP Research and Development Corporation Program of Iran under grant no. 20132014-Persian Gulf-1A.

\section{REFERENCES}

[1] T. R. Kurfess, Robotics and automation handbook: CRC, 2005.

[2] J. J. E. Slotine and W. Li, Applied nonlinear control vol. 461: Prentice hall Englewood Cliffs, NJ, 1991. 
[3] K. Ogata, Modern control engineering: Prentice Hall, 2009.

[4] J. J. D'Azzo, C. H. Houpis and S. N. Sheldon, Linear control system analysis and design with MATLAB: CRC, 2003.

[5] B. Siciliano and O. Khatib, Springer handbook of robotics: Springer-Verlag New York Inc, 2008.

[6] F. T. Cheng, T. L. Hour, Y. Y. Sun and T. H. Chen, "Study and resolution of singularities for a 6-DOF PUMA manipulator," Systems, Man, and Cybernetics, Part B: Cybernetics, IEEE Transactions on, No. 2, vol. 27, pp. 332-343, 2002.

[7] M. W. Spong and M. Vidyasagar, Robot dynamics and control: Wiley-India, 2009.

[8] A. Vivas and V. Mosquera, "Predictive functional control of a PUMA robot," Conference Proceedings, 2005.

[9] D. Nguyen-Tuong, M. Seeger and J. Peters, "Computed torque control with nonparametric regression models," IEEE conference proceeding, 2008, pp. 212-217.

[10] Farzin Piltan , N. Sulaiman, Zahra Tajpaykar, Payman Ferdosali, Mehdi Rashidi, "Design Artificial Nonlinear Robust Controller Based on CTLC and FSMC with Tunable Gain,” International Journal of Robotic and Automation, 2 (3): 205-220, 2011.

[11] Farzin Piltan, A. R. Salehi and Nasri B Sulaiman.," Design artificial robust control of second order system based on adaptive fuzzy gain scheduling," world applied science journal (WASJ), 13 (5): 1085-1092, 2011.

[12] Farzin Piltan, N. Sulaiman, Atefeh Gavahian, Samira Soltani, Samaneh Roosta, "Design Mathematical Tunable Gain PID-Like Sliding Mode Fuzzy Controller with Minimum Rule Base," International Journal of Robotic and Automation, 2 (3): 146-156, 2011.
[13] Farzin Piltan , M. Akbari, M. Piran, M. Bazrega "Design Model Free Switching Gain Scheduling Baseline Controller with Application to Automotive Engine," International Journal of Information Technology and Computer Science (IJITCS), 5 (1): 65-76, 2013.

[14] Farzin Piltan , M. Piran, M. Bazregar, M. Akbari "Design High Impact Fuzzy Baseline Variable Structure Methodology to Artificial Adjust Fuel Ratio ," International Journal of Intelligent Systems and Applications(IJISA), 5 (2): 59-70, 2013.

[15] Farzin Piltan, N. Sulaiman , Arash Zargari, Mohammad Keshavarz, Ali Badri , "Design PIDLike Fuzzy Controller With Minimum Rule Base and Mathematical Proposed On-line Tunable Gain: Applied to Robot Manipulator," International Journal of Artificial intelligence and expert system, 2 (4):184-195, 2011.

[16] Farzin Piltan, Nasri Sulaiman, M. H. Marhaban and R. Ramli, "Design On-Line Tunable Gain Artificial Nonlinear Controller," Journal of Advances In Computer Research, 2 (4): 75-83, 2011.

[17] Farzin Piltan, N. Sulaiman, Payman Ferdosali, Iraj Assadi Talooki, "Design Model Free Fuzzy Sliding Mode Control: Applied to Internal Combustion Engine," International Journal of Engineering, 5 (4):302-312, 2011.

[18] Farzin Piltan, N. Sulaiman, Samaneh Roosta, M.H. Marhaban, R. Ramli, "Design a New Sliding Mode Adaptive Hybrid Fuzzy Controller," Journal of Advanced Science \& Engineering Research , 1 (1): 115-123, 2011.

[19] Farzin Piltan, Atefe Gavahian, N. Sulaiman, M.H. Marhaban, R. Ramli, "Novel Sliding Mode Controller for robot manipulator using FPGA," Journal of Advanced Science \& Engineering Research, 1 (1): 1-22, 2011. 
[20] Farzin Piltan, N. Sulaiman, A. Jalali \& F. Danesh Narouei, "Design of Model Free Adaptive Fuzzy Computed Torque Controller: Applied to Nonlinear Second Order System," International Journal of Robotics and Automation, 2 (4):232-244, 2011.

[21] Farzin Piltan, N. Sulaiman, Iraj Asadi Talooki, Payman Ferdosali, "Control of IC Engine: Design a Novel MIMO Fuzzy Backstepping Adaptive Based Fuzzy Estimator Variable Structure Control ," International Journal of Robotics and Automation, 2 (5):360-380, 2011.

[22] Farzin Piltan, N. Sulaiman, Payman Ferdosali, Mehdi Rashidi, Zahra Tajpeikar, “Adaptive MIMO Fuzzy Compensate Fuzzy Sliding Mode Algorithm: Applied to Second Order Nonlinear System," International Journal of Engineering, 5 (5): 380-398, 2011.

[23] Farzin Piltan, N. Sulaiman, Hajar Nasiri, Sadeq Allahdadi, Mohammad A. Bairami, "Novel Robot Manipulator Adaptive Artificial Control: Design a Novel SISO Adaptive Fuzzy Sliding Algorithm Inverse Dynamic Like Method," International Journal of Engineering, 5 (5): 399-418, 2011.

[24] Samira Soltani \& Farzin Piltan, "Design Artificial Nonlinear Controller Based on Computed Torque like Controller with Tunable Gain”. World Applied Science Journal,14 (9): 1306-1312, 2011.

[25] Farzin Piltan, N. Sulaiman, Sadeq Allahdadi, Mohammadali Dialame, Abbas Zare, "Position Control of Robot Manipulator: Design a Novel SISO Adaptive Sliding Mode Fuzzy PD Fuzzy Sliding Mode Control," International Journal of Artificial intelligence and Expert System, 2 (5):208-228, 2011.

[26] Farzin Piltan, SH. Tayebi HAGHIGHI, N. Sulaiman, Iman Nazari, Sobhan Siamak, "Artificial Control of PUMA Robot Manipulator: A-Review of Fuzzy Inference Engine And Application to Classical Controller ," International Journal of Robotics and Automation, 2 (5):401-425, 2011.
[27] Farzin Piltan, N. Sulaiman, Abbas Zare, Sadeq Allahdadi, Mohammadali Dialame, "Design Adaptive Fuzzy Inference Sliding Mode Algorithm: Applied to Robot Arm," International Journal of Robotics and Automation , 2 (5): 283-297, 2011.

[28] Farzin Piltan, Amin Jalali, N. Sulaiman, Atefeh Gavahian, Sobhan Siamak, "Novel Artificial Control of Nonlinear Uncertain System: Design a Novel Modified PSO SISO Lyapunov Based Fuzzy Sliding Mode Algorithm ," International Journal of Robotics and Automation, 2 (5): 298-316, 2011.

[29] Farzin Piltan, N. Sulaiman, Amin Jalali, Koorosh Aslansefat, "Evolutionary Design of Mathematical tunable FPGA Based MIMO Fuzzy Estimator Sliding Mode Based Lyapunov Algorithm: Applied to Robot Manipulator," International Journal of Robotics and Automation, 2 (5):317-343, 2011.

[30] Farzin Piltan, N. Sulaiman, Samaneh Roosta, Atefeh Gavahian, Samira Soltani, "Evolutionary Design of Backstepping Artificial Sliding Mode Based Position Algorithm: Applied to Robot Manipulator," International Journal of Engineering, 5 (5):419-434, 2011.

[31] Farzin Piltan, N. Sulaiman, S.Soltani, M. H. Marhaban \& R. Ramli, "An Adaptive sliding surface slope adjustment in PD Sliding Mode Fuzzy Control for Robot Manipulator," International Journal of Control and Automation , 4 (3): 65-76, 2011.

[32] Farzin Piltan, N. Sulaiman, Mehdi Rashidi, Zahra Tajpaikar, Payman Ferdosali, "Design and Implementation of Sliding Mode Algorithm: Applied to Robot Manipulator-A Review ," International Journal of Robotics and Automation, 2 (5):265-282, 2011

[33] Farzin Piltan, N. Sulaiman, Amin Jalali, Sobhan Siamak, and Iman Nazari, "Control of Robot Manipulator: Design a Novel Tuning MIMO Fuzzy Backstepping Adaptive Based Fuzzy Estimator 
Variable Structure Control ," International Journal of Control and Automation, 4 (4):91-110, 2011.

[34] Farzin Piltan, N. Sulaiman, Atefeh Gavahian, Samaneh Roosta, Samira Soltani, "On line Tuning Premise and Consequence FIS: Design Fuzzy Adaptive Fuzzy Sliding Mode Controller Based on Lyaponuv Theory," International Journal of Robotics and Automation, 2 (5):381-400, 2011.

[35] Farzin Piltan, N. Sulaiman, Samaneh Roosta, Atefeh Gavahian, Samira Soltani, "Artificial Chattering Free on-line Fuzzy Sliding Mode Algorithm for Uncertain System: Applied in Robot Manipulator," International Journal of Engineering, 5 (5):360-379, 2011.

[36] Farzin Piltan, N. Sulaiman and I.AsadiTalooki, "Evolutionary Design on-line Sliding Fuzzy Gain Scheduling Sliding Mode Algorithm: Applied to Internal Combustion Engine," International Journal of Engineering Science and Technology, 3 (10):7301-7308, 2011.

[37] Farzin Piltan, Nasri B Sulaiman, Iraj Asadi Talooki and Payman Ferdosali.," Designing On-Line Tunable Gain Fuzzy Sliding Mode Controller Using Sliding Mode Fuzzy Algorithm: Applied to Internal Combustion Engine,” world applied science journal (WASJ), 15 (3): 422-428, 2011.

[38] Farzin Piltan and Shahnaz Tayebi Haghighi, "Design Gradient Descent Optimal Sliding Mode Control of Continuum Robot, IAES-International Journal of Robotics and Automation, No.4, Vol. 1, pp. 175-189, 2012.

[39] M. Bazregar, Farzin Piltan, A. Nabaee and M. Ebrahimi, " Parallel Soft Computing Control Optimization Algorithm for Uncertainty Dynamic Systems," International Journal of Advanced Science and Technology (IJAST), Vol. 51, pp. 93106, 2013.

[40] Farzin Piltan, N. Sulaiman, M. H. Marhaban, Adel Nowzary, Mostafa Tohidian," "Design of FPGA based sliding mode controller for robot manipulator," International Journal of Robotic and Automation, 2 (3): 183-204, 2011.

[41] Farzin Piltan, M. Mirzaie, F. Shahriyari, Iman Nazari \& S. Emamzadeh." Design Baseline Computed Torque Controller" International Journal of Engineering, 3(3): 2012.

[42] Farzin Piltan, H. Rezaie, B. Boroomand, Arman Jahed," Design robust back stepping online tuning feedback linearization control applied to IC engine," International Journal of Advance Science and Technology, 42: 183-204, 2012.

[43] Farzin Piltan, I. Nazari, S. Siamak, P. Ferdosali ,"Methodology of FPGA-based mathematical error-based tuning sliding mode controller" International Journal of Control and Automation, 5(1): 89-110, 2012.

[44] Farzin Piltan, M. A. Dialame, A. Zare, A. Badri ,'Design Novel Lookup table changed Auto Tuning FSMC: Applied to Robot Manipulator" International Journal of Engineering, 6(1): 25-40, 2012.

[45] Farzin Piltan, B. Boroomand, A. Jahed, H. Rezaie ,"Methodology of Mathematical ErrorBased Tuning Sliding Mode Controller' International Journal of Engineering, 6(2): 96-112, 2012.

[46] Farzin Piltan, F. Aghayari, M. R. Rashidian, M. Shamsodini, ”A New Estimate Sliding Mode Fuzzy Controller for Robotic Manipulator" International Journal of Robotics and Automation, 3(1): 45-58, 2012.

[47] Farzin Piltan, M. Keshavarz, A. Badri, A. Zargari , ’Design novel nonlinear controller applied to robot manipulator: design new feedback linearization fuzzy controller with minimum rule base tuning method" International Journal of Robotics and Automation, 3(1): 1-18, 2012.

[48] Piltan, F., et al. "Design sliding mode controller for robot manipulator with artificial tunable gain". 
Canaidian Journal of pure and applied science, 5 (2), 1573-1579, 2011.

[49] Farzin Piltan, A. Hosainpour, E. Mazlomian, M.Shamsodini, M.H Yarmahmoudi. "Online Tuning Chattering Free Sliding Mode Fuzzy Control Design: Lyapunov Approach" International Journal of Robotics and Automation, 3(3): 2012.

[50] Farzin Piltan, M.H. Yarmahmoudi, M. Shamsodini, E.Mazlomian, A.Hosainpour. " PUMA-560 Robot Manipulator Position Computed Torque Control Methods Using MATLAB/SIMULINK and Their Integration into Graduate Nonlinear Control and MATLAB Courses" International Journal of Robotics and Automation, 3(3): 2012.

[51] Farzin Piltan, R. Bayat, F. Aghayari, B. Boroomand. "Design Error-Based Linear ModelFree Evaluation Performance Computed Torque Controller" International Journal of Robotics and Automation, 3(3): 2012.

[52] Farzin Piltan, S. Emamzadeh, Z. Hivand, F. Shahriyari \& Mina Mirazaei. " PUMA-560 Robot Manipulator Position Sliding Mode Control Methods Using MATLAB/SIMULINK and Their Integration into Graduate/Undergraduate Nonlinear Control, Robotics and MATLAB Courses" International Journal of Robotics and Automation, 3(3): 2012.

[53] Farzin Piltan, J. Meigolinedjad, S. Mehrara, S. Rahmdel. "Evaluation Performance of $2^{\text {nd }}$ Order Nonlinear System: Baseline Control Tunable Gain Sliding Mode Methodology” International Journal of Robotics and Automation, 3(3): 2012.

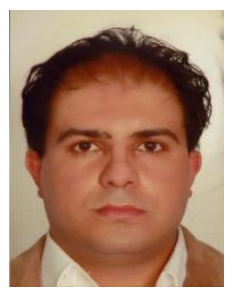

Afsaneh Salehi is a computer and information technology researcher at research and development company SSP. Co. She is an expert artificial intelligence and control engineer in this company. Her research activities deal with the robotic control, artificial intelligence and expert system.

Farzin Piltan was born on 1975, Shiraz, Iran. In 2004 he is jointed the research and development company, SSP Co, Shiraz, Iran. In addition to 7 textbooks, Farzin Piltan is the main author of more than 70 scientific papers in refereed journals. He is editorial board of international journal of control and automation (IJCA), editorial board of International Journal of Intelligent System and Applications (IJISA), editorial board of IAES international journal of robotics and automation, editorial board of International Journal of Reconfigurable and Embedded Systems and reviewer of (CSC) international journal of robotics and automation. His main areas of research interests are nonlinear control, artificial control system and applied to FPGA, robotics and artificial nonlinear control and IC engine modelling and control.

Mahmoud Mousavi is a control and automation researcher at research and development company SSP. Co. $\mathrm{He}$ is an expert in nonlinear control, artificial intelligence and expert systems. His research activities deal with the nonlinear robotic control, artificial intelligence and expert system.

Arzhang Khajeh is an electronic researcher at research and development company SSP. Co. He is an expert in control systems, artificial intelligence and expert systems in this company. His research activities deal with the robotic control, artificial intelligence and expert system.

Mohammad Reza Rashidian is a power electronic researcher at research and Development Company SSP. Co. Mohammad Reza is the main author of more than 3 scientific papers in refereed journals. His research activities deal with the nonlinear modeling, robotic control, artificial intelligence and expert system. 